\title{
Juan Ossio, Etnografía de la cultura andina. Lima: Fondo Editorial del Congreso del Perú. 2018. 514 p.
}

La carátula del libro ya comienza siendo polémica, de título Etnografía de la cultura andina, y como autor, Juan Ossio, presentando su particular punto de vista de una etnografía de lo que en el libro se describe como una cultura andina.

El libro presenta efectivamente un caso etnográfico, el que Ossio registró en Andamarca, centrado en el orden estructural del parentesco (con los recordados cuadros de triángulos y círculos incluidos) y en la economía ritual de la población. Perspectiva polémica: esta metodología había estado ausente en las investigaciones recientes que se centran en un aspecto del estudio de comunidad. Hoy en día, la gran etnografía o la etnografía totalizadora ha retrocedido en favor de estudios mucho más focalizados en aspectos sociales relacionados con la manera como las comunidades se relacionan con el Estado, cómo se articulan las relaciones políticas, la perspectiva de género, la integración al mercado, los desafíos del urbanismo, la constitución de territorialidades negociadas, la migración y las organizaciones que implica, los sistemas de salud y las demandas políticas.

La segunda polémica es el uso de «mundo andino» como categoría a estudiar. El autor busca demostrar que aquello llamado «mundo andino» no es una delimitación geográfica sino cultural, una matriz que unifica un territorio cultural aparentemente muy diverso. ¿Se puede hablar de la matriz andina como un eje articulador de una sola cultura?

Esta pretensión busca, entonces, articular las etnografías que se habían hecho en territorio andino y ubicarlas en una misma dimensión con distintas perspectivas. Una forma de evitar lo que despectivamente Edmond Leach catalogó como «coleccionismo de mariposas» cuando se producen de distintos proyectos de investigación que no tienen interconexión entre sí, en espera de que alguien haga una síntesis teórica.

La tercera y más grande polémica viene con el nombre del autor, Juan Ossio, quien se ha propuesto hacer una síntesis de lo que él denomina «el mundo andino», que combina una perspectiva histórica vinculando la etnografía con la etnohistoria, la paleografía y la deconstrucción de la crónica de Guamán Poma, junto con un ángulo estructural al enfocarse en la red generada por el parentesco. Polémico en el sentido de querer encontrar continuidad histórica y prehispánica en un grupo social que ha luchado por integrarse a la comunidad nacional lejos de quedarse congelado en el tiempo. 
Ossio sintetiza cincuenta años enseñando un curso con nombre similar, condensando en una obra monumental no solo el resultado de sus investigaciones sino de su particular punto de vista. Comenzando por la idea de etnografía que se hace evidente en la experiencia del autor en la comunidad ayacuchana de Andamarca, en donde se traslucen, por un lado, las grandes influencias del autor. Su aproximación a la historia en la herencia académica de su maestro Edward Evan Evans Pritchard, en Oxford, donde la perspectiva histórica británica se refleja en el paralelo que el autor observa con su otro maestro espiritual, el cronista Felipe Guaman Poma de Ayala.

Es en esta perspectiva que el libro avanza, haciendo prácticamente un paralelo con la Nueva Crónica y Buen Gobierno de Guaman Poma a partir de una afirmación social: el peligro de la homogenización cultural en la historia peruana, una historia del indigenismo peruano, una parte propiamente etnográfica, una interpretación de la cosmovisión andina (usando precisamente a Guaman Poma y su crónica como ejemplo) y una perspectiva de la economía campesina y las relaciones interétnicas.

El tono en una primera parte es, como lo fue en general la crónica de Guaman Poma, de observación política. Hay dos tipos de homogeneización: una que Ossio denuncia y otra que Ossio afirma y defiende. La primera es el proceso de occidentalización que ha existido desde el violento encuentro de dos mundos y se mantiene vigente aun en la poscolonialidad. Aquí hay una demanda por la no inclusión de la diferencia en los proyectos políticos occidentales y el etnocentrismo característico del Estado peruano. Paradójicamente hay una segunda homogeneidad retratada en el libro y es, como siempre, el aspecto más polémico que Ossio ha despertado en sus detractores. Ossio piensa que sí y expone de manera demostrativa sus argumentos, que van desde la existencia de horizontes culturales previa a la llegada de los españoles, la existencia de un líder integrador y ritual precisamente antes de la conquista, la matriz económica conservada en la Colonia y la estructura colonial toledana de la comunidad en el territorio andino.

El libro también nos lleva a visitar dos perspectivas, un eco del estructural funcionalismo basado en la descendencia por parte de Radcliffe Brown, y es cuando se aplica la teoría del parentesco para entender las reglas de herencia, las características percibidas de la descendencia y la conformación de grupos locales a través del tiempo. Posteriormente hay una influencia del estructuralismo francés de Levi-Strauss, que llega a través del trabajo de Tom Zuidema y que aplica a la comunidad andina tomando en cuenta una perspectiva de alianza entre grupos a partir de cuadros de parentesco que enarbolan un tejido social a través 
de las relaciones matrimoniales que dividen en forma dual a la sociedad y que a la larga generan prohibiciones y mandatos, obligaciones rituales y distintos tipos de filiación asociadas con la localidad de los miembros de la pareja.

Comunidades articuladas a reglas de parentesco que permitan generar un mapa de estructura es algo que hace tiempo no veíamos en la antropología estructural, especialmente desde la irrupción de la posmodernidad en la investigación etnográfica, la inclusión de Clifford Geertz en su propia descripción densa de gallos de pelea en Bali y el énfasis de Renato Rosaldo a incidir en los puntos de vista subjetivos del investigador y el investigado.

La aproximación a la posmodernidad de Ossio se ha dado en su investigación anterior, referida a los Israelitas del Nuevo Pacto Universal, que en este libro reaparecen como parte de la revisión de la concepción del tiempo circular y la posibilidad del retorno del inca como héroe cultural en el imaginario andino.

Finalizando el libro me quedan ciertas memorias que, como parte de la revisión, quisiera compartir. En primer lugar, es un texto enciclopédico, una suerte de enorme recurso bibliográfico donde se pueden encontrar temas que van desde la perspectiva de los indigenistas hasta cuadros de parentesco, perspectivas legales y textos sobre mesianismo. La pretensión clara es servir de guía a quienes busquen distintas perspectivas sobre la antropología peruana y es evidente que sintetiza décadas de enseñanza de un curso.

En segundo lugar, la perspectiva estructuralista usada por Ossio y su defensa a través de la etnografía de una continuidad cultural ha sido discutida muchas veces desde otras perspectivas centradas en la subalternidad, las instituciones políticas, el manejo del poder y la violencia política que vivió la comunidad andina en un pasado reciente.

Sin embargo, también recuerdo que, en una clase de técnicas de promoción social, la profesora Cecilia Rivera invitó a su colega Carlos Monge, quien estaba trabajando en desarrollo social, y nos comentó la necesidad de tener siempre presentes los alcances clásicos de la antropología, puesto que hay muchas dimensiones de las estructuras sociales que aún pueden ser entendidas desde esta perspectiva.

En tercer lugar, quisiera observar que el libro presenta un estudio etnográfico que estará allí, dando una fotografía de una comunidad o de un grupo religioso en su momento, y que aun cuando se pueda discrepar con el modo de aproximación, queda abierta a la posibilidad de ser un rico espacio de reinterpretación y de debate.

Este es y será siempre el valor de la buena etnografía. En Andamarca, durante el proceso de retorno tras el período de violencia, se realizaron las ceremonias 
relacionadas con el agua y la limpia de acequia. Uno de los elementos que llamaba mi atención, junto al huayla ichu y las ofrendas, era el libro sobre el parentesco andamarquino que Juan Ossio no hacía mucho había publicado, abierto en la mesa ritual. Los comuneros jóvenes lo estaban usando como manual para poder armar la mesa ceremonial antes de limpiar los canales.

\section{Alexander Huerta-Mercado Pontificia Universidad Católica del Perú}

\section{Resumen}

El libro reúne los trabajos realizados por Juan Ossio a lo largo de cincuenta años; desarrollados a partir de sus investigaciones de campo, análisis de documentos históricos y testimonios personales. El autor se sirve del método etnográfico e histórico para identificar y analizar las características comunes que articulan diferentes aspectos de organización económica, política, tradicional, ritual y de parentesco en las comunidades del territorio andino bajo características culturales que se acercan a una matriz.

Palabras clave: andino, cultura, etnografía, Juan Ossio. 